\title{
Data for Users of Handheld Ion Mobility Spectrometers
}

\author{
Keith A. Daum \\ Sandra L. Fox
}

May 2008

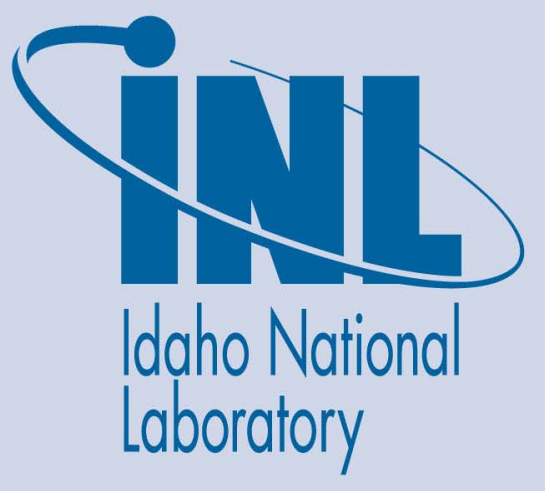

The INL is a U.S. Department of Energy National Laboratory operated by Battelle Energy Alliance 


\title{
Data for Users of Handheld Ion Mobility Spectrometers
}

Keith A. Daum

Sandra L. Fox

May 2008

\author{
Idaho National Laboratory \\ Idaho Falls, Idaho 83415 \\ http://www.inl.gov
}




\section{DISCLAIMER}

This information was prepared as an account of work sponsored by an agency of the U.S. Government. Neither the U.S. Government nor any agency thereof, nor any of their employees, makes any warranty, expressed or implied, or assumes any legal liability or responsibility for the accuracy, completeness, or usefulness, of any information, apparatus, product, or process disclosed, or represents that its use would not infringe privately owned rights. References herein to any specific commercial product, process, or service by trade name, trademark, manufacturer, or otherwise, does not necessarily constitute or imply its endorsement, recommendation, or favoring by the U.S. Government or any agency thereof, or any company affiliated with Idaho National Laboratory. The views and opinions of authors expressed herein do not necessarily state or reflect those of the U.S. Government or any agency thereof. 



\section{Data for Users of Handheld Ion Mobility Spectrometers}

INL/EXT-08-14265

May 2008

Approved by:

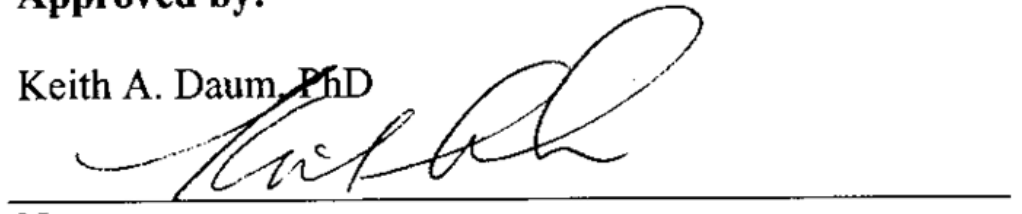

Name

$\frac{\text { May } 22,200 \mathrm{f}}{\text { Date }}$ 



\section{EXECUTIVE SUMMARY}

Chemical detection technology end-user surveys conducted by Idaho National Laboratory (INL) in 2005 and 2007 indicated that first responders believed manufacturers' claims for instruments sometimes were not supported in field applications, and instruments sometimes did not meet their actual needs. Based on these findings, the Department of Homeland Security (DHS) asked INL to conduct a similar survey for handheld ion mobility spectrometers (IMS), which are used by a broad community of first responders as well as for other applications. To better access this broad community, the INL used the Center for Technology Commercialization, Inc. (CTC), Public Safety Technology Center (PSTC) to set up an online framework to gather information from users of handheld IMS units. This framework (Survey Monkey) was then used to perform an online Internet survey, augmented by e-mail prompts, to get information from first responders and personnel from various agencies about their direct experience with handheld IMS units. Overall, 478 individuals responded to the survey. Of these, 174 respondents actually owned a handheld IMS. Performance and satisfaction data from these 174 respondents are captured in this report.

The survey identified the following observations:

- The most common IMS unit used by respondents was the Advanced Portable Detector (APD-2000), followed by ChemRae, Sabre 4000, Sabre 2000, Draeger Multi IMS, Chemical Agent Monitor-2, Chemical Agent Monitor, Vapor Tracer, and Vapor Tracer-2.

- The primary owners were HazMat teams (20\%), fire services (14\%), local police $(12 \%)$, and sheriffs' departments $(9 \%)$.

- IMS units are seldom used as part of an integrated system for detecting and identifying chemicals but instead are used independently.

- Respondents are generally confused about the capabilities of their IMS unit. This is probably a result of lack of training.

- Respondents who had no training or fewer than 8 hours were not satisfied with the overall operation of the handheld IMS unit.

- IMS units were used for detecting a range of analytes. The most common use was for detection of hazardous chemicals, followed by detection of explosives, illicit drugs, chemical warfare, nerve agents, and radiation. One IMS unit had dual capability as a radiation detector.

- Respondents who did not own an IMS listed prohibitive cost of equipment as the main factor for not having one.

- Respondents who were highly satisfied with the overall operation of the handheld IMS obtained the IMS through a direct purchase. In comparison, the respondents who were not satisfied had obtained the handheld IMS through a DHS grant. 


\section{ACKNOWLEDGMENTS}

We would like to thank the HazMat personnel, first responders, fire fighters, local and state police, sheriffs, border patrol agents, and other agency personnel for completing the online handheld IMS survey. We also thank Melinda Cook and Thomas Creighton from the Center for Technology Commercialization, Inc., Public Safety Technology Center, for promoting the handheld IMS survey. 


\section{CONTENTS}

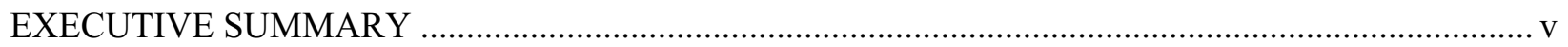

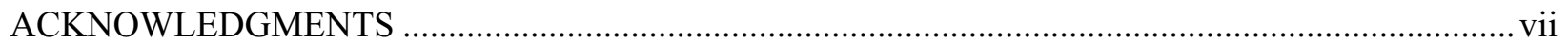

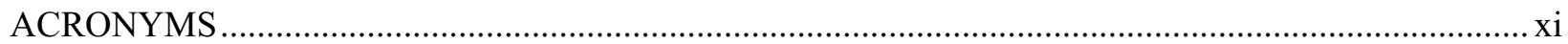

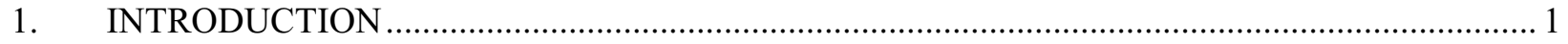

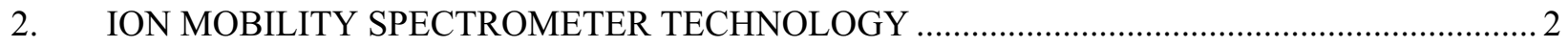

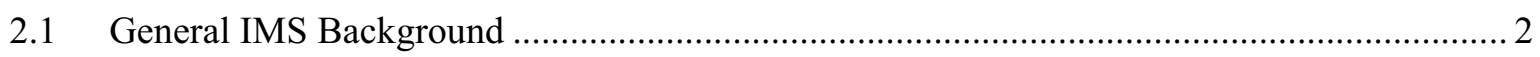

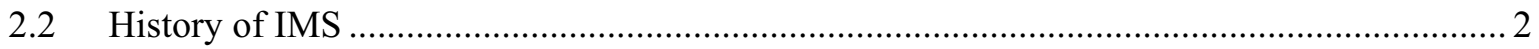

2.3 Basic Principles of Ion Mobility Spectrometry .................................................................. 3

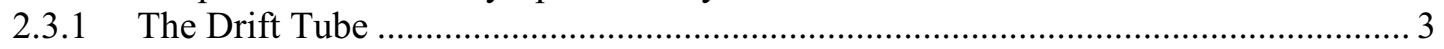

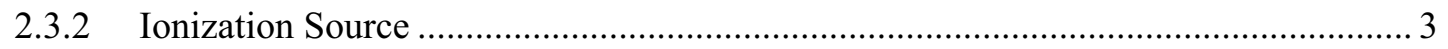

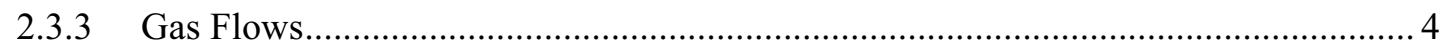

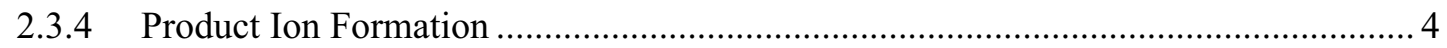

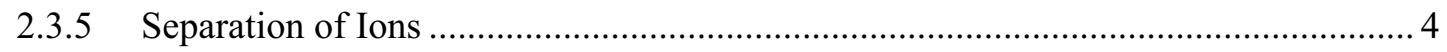

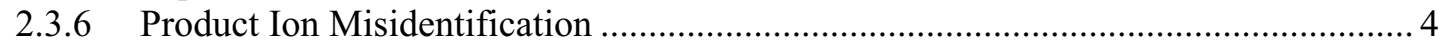

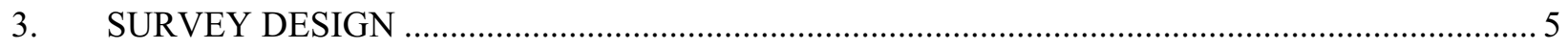

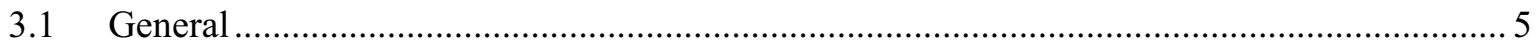

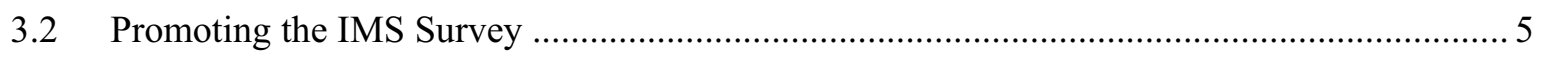

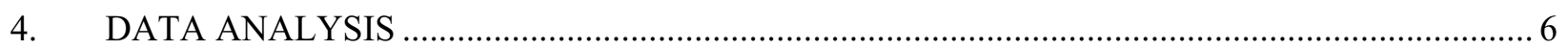

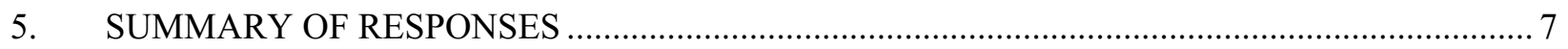

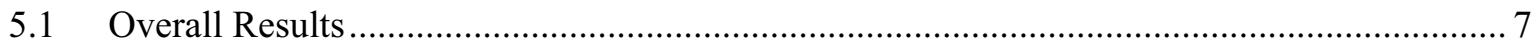

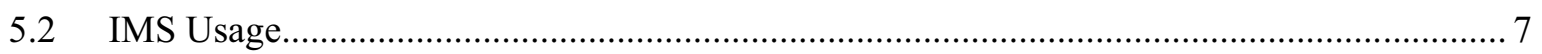

5.2.1 IMS Models Used in Regions and Cities of Varying Populations .............................. 8

5.2.2 Number of Field Operations that Survey Respondents Perform Monthly .................. 9

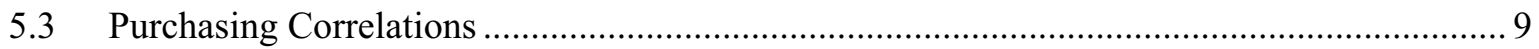

5.3.1 Reasons for Purchasing IMS Technology ..................................................... 9

5.3.2 Why Some Agencies Do Not Own IMS Technology .......................................... 9

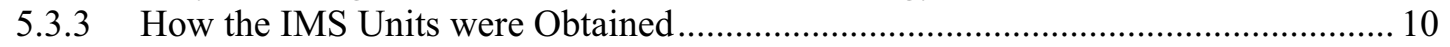

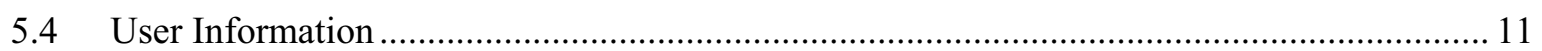

5.4.1 Interferents or Limitations Noted About IMS Use ............................................ 11

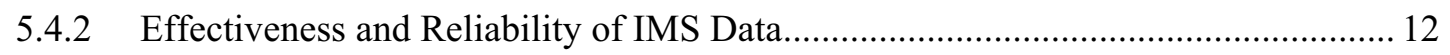

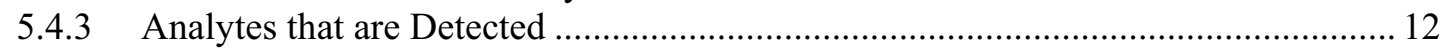

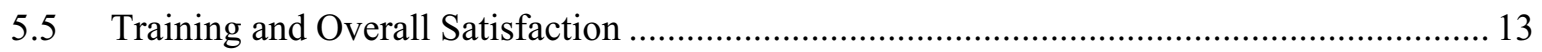

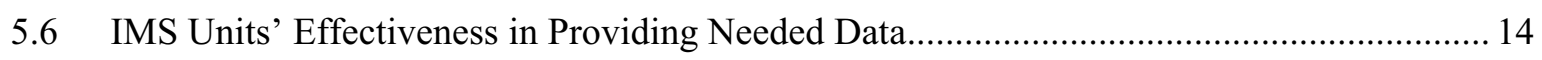

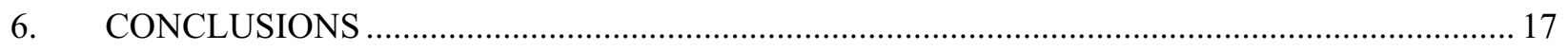

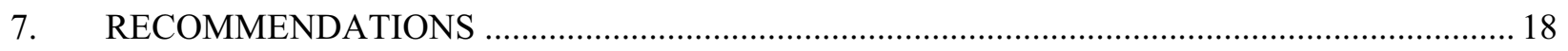

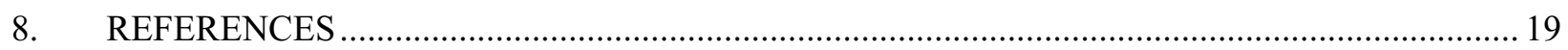




\section{FIGURES}

Figure 1. Basic configuration of an ion mobility spectrometer. ................................................................. 3

Figure 2. Total handheld IMS units owned distributed by model............................................................ 7

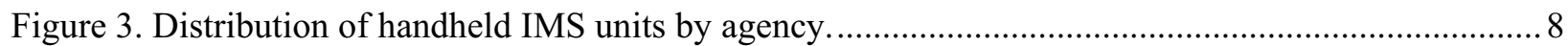

Figure 4. Distribution of models of IMS units owned based on population. .............................................. 8

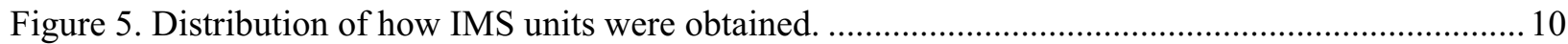

Figure 6. Distribution of types of handheld IMS limitations reported.................................................... 11

Figure 7. Distribution of types of IMS limitations reported based on responding agency...................... 11

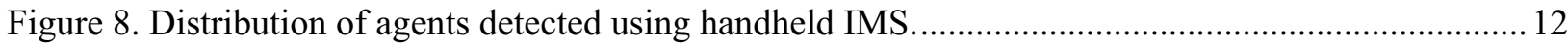

\section{TABLES}

Table 1. Distribution of responses identifying how specific models of IMS units were obtained. 10

Table 2. Distribution of responses identifying which analytes are detected based on specific IMS models .13

Table 3. Distribution of survey respondents and satisfaction with their handheld IMS units. .13

Table 4. Distribution of reported amount of training received based on individual IMS unit. 14 


\section{ACRONYMS}

AEL authorized equipment list

CTC/PSTC Center for Technology Commercialization, Inc., Public Safety Technology Center

APD-2000 Advanced Portable Detector-2000

CAM Chemical Agent Monitor

CAM-2 Chemical Agent Monitor-2

DHS Department of Homeland Security

HazMat Hazardous Materials

LCD Lightweight Chemical Detector

IMS ion mobility spectrometer

INL Idaho National Laboratory 


\section{Data for Users of Handheld Ion Mobility Spectrometers}

\section{INTRODUCTION}

Every day across the U.S. and around the world, analytical chemistry data is used to help decision makers understand a situation and develop plans and strategies for action. The decisions may concern the safety and health of humans, the integrity of the environment, or product reliability. Because of the number of steps in the analytical chemistry data process collection (sample collection and transport, sample analysis in a laboratory, data analysis, and data transmittal), the resulting data needed to make these decisions may take hours or days to be delivered to a decision maker. The advent of simple, portable, analytical instruments has dramatically changed this process. Chemical data can now be taken on site, and decisions that previously took days can now be made in near real time in the field. This evaluation covers one group of these portable analytical instruments-handheld ion mobility spectrometers (IMS) — which are being used increasingly in field operations.

The Department of Homeland Security (DHS) wants first responders to have appropriate technologies for evaluating potential threats. Chemical detection technology end-user surveys conducted by Idaho National Laboratory (INL) in 2005 and 2007 indicated that first responders believed manufacturers' claims for instruments sometimes were not supported in field applications, and instruments sometimes did not meet their actual needs. ${ }^{1,2}$ Based on these finding, INL was given the task of surveying the community of handheld ion mobility spectrometer owners to gain hands-on user information about handheld IMS units. The goal was to gather IMS user information from a broad community of first responders to help guide future equipment research and development and develop guidelines to assist agencies in selecting dependable field instruments.

This report focuses on handheld IMS equipment. Information about handheld units was collected using an online survey tool that included a set of about 30 questions. Survey respondents who owned IMS technology identified the IMS unit their agency owned, defined IMS usage, limitations, described their experience with a handheld IMS, provided input on purchasing, and gave input on their overall level of satisfaction with the technology. 


\section{ION MOBILITY SPECTROMETER TECHNOLOGY}

\subsection{General IMS Background}

IMS technology has numerous field applications. Airport security personnel use IMS data to decide if luggage contains explosives or if passengers have recently worked with explosives. Border guards use IMS data to help identify people who are carrying illegal drugs as they enter the U.S. Incident commanders and first responders are also beginning to use IMS data to make decisions about chemicals present in disasters and terrorist events. IMS is a good candidate for these applications because it is a rugged, portable, sensitive, and relatively inexpensive, field instrument capable of trace organic analysis for explosives, drugs, and chemicals of interest to first responders. ${ }^{3,4,5}$

Though IMS has advantages that make it attractive for collecting field analytical chemistry data, it does have limitations. One of the notable problems is resolution of similar analytes and masking that results from interfering compounds. ${ }^{3,4,5,6,7,8}$ Masking can take place through overlap of analyte response or when an analyte does not ionize ${ }^{9}$ In addition, the responses from IMS analyses are not always predictable. ${ }^{7,10}$ These limitations are generally associated with a lack of understanding about the chemical ionization mechanisms at the atmospheric pressure conditions that determine IMS responses. ${ }^{4}$ To help the reader better understand some of the advantages and limitations, this section provides an overview of IMS technology, including history and basic operating principles.

\subsection{History of IMS}

The basis for IMS measurements involves formation and separation of ions at atmospheric pressure. ${ }^{11}$ The development of IMS instrumentation began in the early 1970s and was also known by two other names: gaseous electrophoresis and plasma chromatography. ${ }^{3}$ The term gaseous electrophoresis highlighted the similarities with liquid-phase electrophoresis, while the term plasma chromatography emphasized the similarity between IMS and chromatographic separations. ${ }^{3}$ Both of these terms were replaced by the name ion mobility spectrometry in the early 1980s. All three terms are used in the early literature and patents.

Several patents defined IMS development. The original patent was filed in 1971 by Cohen, ${ }^{11}$ for Time of Flight Ion Analysis with a Pulsed Ion Source Employing Ion-Molecule Reactions. This patent established the basis for creating ions and separating them in a weak electric field at atmospheric pressure. Also in 1971, Carroll, Cohen, and Wernlund ${ }^{12}$ filed a patent for Enhanced Resolution of Measurements of Trace Gases Which Undergo Ion-Molecule Reactions. This patent described the role of IMS in analyzing trace substances. This patent also first described ion-molecule reactions that led to the formation of product ions, which are the central topic of this report. In 1972, Carroll ${ }^{13}$ filed a patent for Apparatus and Methods for Separating, Detecting, and Measuring Trace Gases, which further described the hardware that now comprises an IMS. This patent established the basic parameters of the weak electric field necessary for separating product ions. Later in 1972, Cohen, Carroll, Wernlund, and Kilpatrick ${ }^{14}$ filed the patent, Apparatus and Methods for Separating, Concentrating, Accelerating, and Measuring Trace Gases, which further defined the weak electric field and clarified how ions are separated and how ions of like mobility can be concentrated. Finally, in 1973 Cohen and Crowe ${ }^{15}$ filed the patent, Apparatus and Methods for Detecting, Separating, Concentrating, and Measuring Electronegative Trace Vapors, which established the role of negative mode IMS in explosives detection.

In addition to instrument design, the other area important to early development of IMS was understanding the fundamental chemistry behind the formation of reactant and product ions. A series of studies to understand the underlying chemical principles of IMS were conducted by Karasek and coworkers in the 1970s. ${ }^{10,16,17,18,19,20,21}$ These studies used IMS instrumentation to investigate the chemistry 
of ion formation at atmospheric pressure. An important outcome of the work by Karasek was understanding that the formation of ions in an IMS instrument depends on the competitive distribution of the available charge among the neutral molecules based on their gas phase acidity (or basicity), electron affinities, and concentrations. ${ }^{4}$

\subsection{Basic Principles of Ion Mobility Spectrometry}

\subsubsection{The Drift Tube}

An IMS consists of simple hardware and typically operates at ambient atmospheric pressure. The critical component of an IMS system is the drift tube, where ions are created and through which ions migrate under a constant electric field. ${ }^{3}$ A schematic of an IMS drift tube is shown in Figure 1.

The two major parts to a drift tube are the region where ionization reactions take place and the drift or separation region. The regions are separated by an electrical shutter, or ion gate. ${ }^{4}$ The ion shutter controls the movement of ions from the ionization region, where the ions are formed, into the drift region, where ions are separated in a weak electric field. ${ }^{5}$ Ions are created by atmospheric pressure chemical ionization reactions, which will be discussed further.

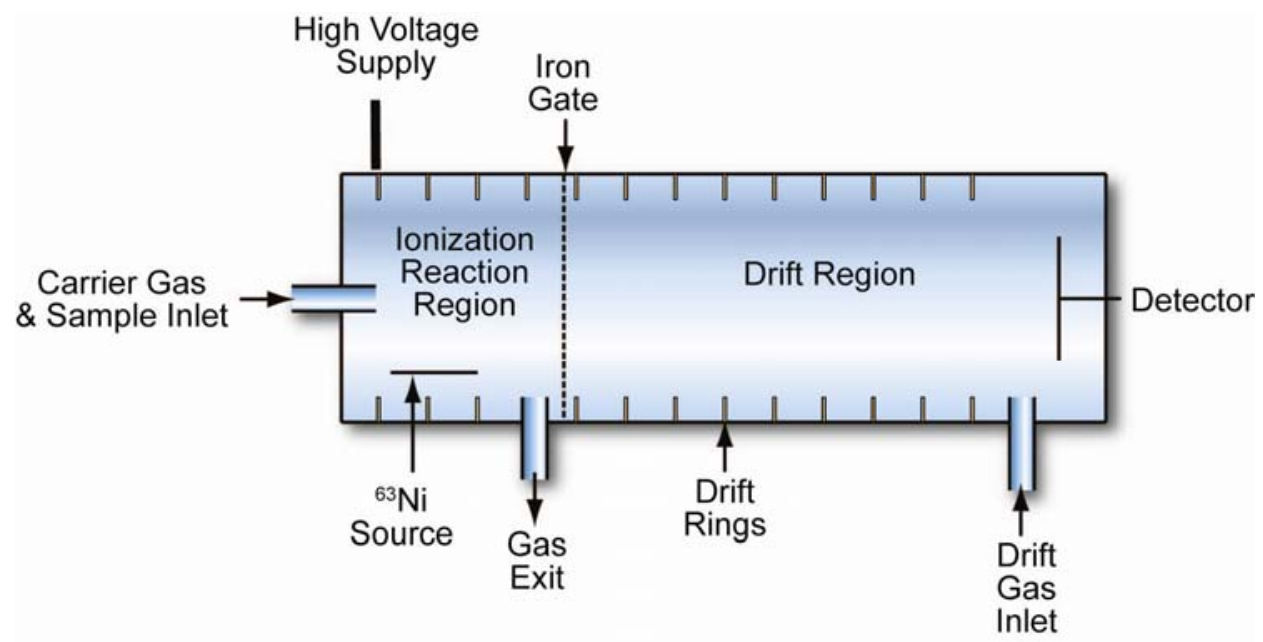

08-GA50290-01

Figure 1. Basic configuration of an ion mobility spectrometer.

In the drift tube, a constant electric field is established by applying voltage to a set of stacked conducting rings, which are separated by an insulating material. The electric field can be configured to have an effect on either cations or anions. Ions created in the ionization region are immediately influenced by the appropriate weak electric field and move toward drift region. An electrical shutter separates the two regions and allows pulses of ions formed in the ionization region into the drift region. The product ions are detected as they collide with a simple Faraday plate detector at the end of the drift tube.

\subsubsection{Ionization Source}

The primary ionization source of the IMS originates the initial pool of charge, which can then be distributed in the formation of thermal electrons, reactant ions, or both. Several sources have been used as the primary ionization source, including thermionic emission, ${ }^{22}$ flame ionization, ${ }^{4}$ photoionization, ${ }^{23}$ surface ionization ${ }^{24}$ laser multiphoton ionization, ${ }^{25}$ electrospray, ${ }^{26}$ and corona-discharge ${ }^{27}$ Early IMS 
instrumentation sometimes involved other sources; ${ }^{63} \mathrm{Ni}$ was the ionization source in the first patent and is still used in some instruments today.

\subsubsection{Gas Flows}

In most IMS designs, there are two gas flows: carrier and drift. The carrier gas, sometimes called the source gas, is used to transport the reagent gases and the sample into the ionization region of the drift tube. Running countercurrent to the carrier gas is the drift gas flow. The drift gas maintains a clean environment in the drift region. The drift gas flow sweeps away any neutrals from the drift region, reducing secondary ion-molecule reactions in the drift tube.

\subsubsection{Product Ion Formation}

Chemical ionization can take place by a number of mechanisms, including electron transfer and charge exchange, decomposition (e.g., proton abstraction), nucleophilic displacement, and clustering or adduct formation. ${ }^{28,29,30,31}$

\subsubsection{Separation of lons}

After formation, ions move under the influence of the electric field. Each ion undergoes a series of molecular-level collisions with buffer gas molecules, while being accelerated by the electric field between collisions. These molecular-level collisions yield a constant ion velocity $\left(v_{d}\right)$ when observed over the time $(t)$ it takes the ion to traverse the length $(L)$ of the drift tube, ${ }^{3}$ which can be shown as

$v_{d}=L / t$.

The $v_{d}$ is directly proportional to the electric field strength $(E)$, which can be shown as

$v_{d}=E K$,

and the proportionality constant is called the ion mobility $(K)$. The analyte product ions are separated

based on their ion mobility in the electric field, which is commonly calculated as

$$
K=v_{d} / E=L / E t .
$$

The ion mobility is commonly adjusted for operating conditions by accounting for variations in temperature and pressure $(P)$ to yield a reduced mobility $\left(K_{o}\right)$. This reduced mobility is used for identification and is essentially constant for an analyte, and can be shown as

$$
K_{o}=K\left(\frac{273}{T}\right)\left(\frac{P}{760}\right) .
$$

\subsubsection{Product Ion Misidentification}

The two basic pathways by which misidentification or masking of analyte responses can take place in IMS analysis are (1) failure of an analyte to form a detectable ion in the presence of a more easily ionized interferent ${ }^{9}$ and (2) when detectable ions are formed by both the analyte and the interfering compound. ${ }^{29}$ Compared to analytical techniques such as mass spectrometry, IMS is an inherently low-resolution technique, and the two detectable ions can have similar collisional and cross-sectional areas that result in overlapping $K_{o}$ values. 


\section{SURVEY DESIGN}

\subsection{General}

To effectively conduct this survey, INL used the Center for Technology Commercialization, Inc. (CTC), Public Safety Technology Center (PSTC) to assist with the survey design and to market the survey. To gather information from users of handheld IMS units, INL used an online Internet survey, Survey Monkey (www.surveymonkey.com), with e-mail prompts to implement the survey online. This method was chosen for its simplicity and efficiency, as well as cost-effectiveness.

The online operation included more than a dozen types of questions (single choice, multiple choice, rating scales, drop-down menus, etc). Quality control was provided in options such as requiring participants to respond to a given question, controlling the flow of the survey with skip logic, and even randomizing choices to eliminate bias. Results could be viewed as they were collected in real time or summarized in live graphs and charts. INL chose to export summary and raw data to Excel and Statistica for additional analysis.

Targeted marketing was conducted to increase the response rate and locate users of IMS technology. An alternative domain was reserved (www.imssurvey.org) to easily re-point respondents to the survey link. In order to obtain candid information, the names of individuals completing the survey and the cities they were from were kept anonymous.

\subsection{Promoting the IMS Survey}

INL promoted the survey using CTC/PSTC-recognized public safety experts in the fields of law enforcement, fire services, and emergency management. The survey was promoted through personal contacts, conferences, online bulletin boards and forums, and e-mail blasts to select subscriber-based databases, all geared toward accessing the first responder community. Specific activities used to promote the survey are as follows:

- E-mail blast (December 19, 2007) of attendees and invitees of the 2007 Technology Critical Incident Preparedness Conference, San Francisco, CA, November 6-9. This e-mail blast reached approximately 17,774 people.

- JUSTNET e-mail blast (November 1, 2007). This e-mail blast reached approximately 4,900 people.

- CTC/PSTC staff attended the 2007 Technology Critical Incident Preparedness Conference, San Francisco, CA, November 6-9. Approximately 1,500 first responders attended. The IMS survey flyer was placed on conference resource table.

- CTC/PSTC staff attended the 2007 Technical Support Working Group Conference, Fort Lauderdale, FL, November 28-30. Approximately 500 first responders attended. The IMS survey flyer was placed on conference resource table, and an announcement was made at the general assembly requesting first responders to take the survey.

- Center for Technology Commercialization (CTC) Website (www.ctc.org).

- Massachusetts Law Enforcement Technology and Training Center website (www.malettsc.org).

- Posting on user forums was implemented on December 14, 2007. 


\section{DATA ANALYSIS}

Data were transferred from Survey Monkey into Excel to prepare most summary tables and graphs. Summary data were then entered into Statistica to run a correlation matrix of all variables to determine significant relations. This was done using the Pearson $\mathrm{r}$, or product-moment correlation coefficient. Graphs, tables, and some correlations are presented throughout the following section. 


\section{SUMMARY OF RESPONSES}

\subsection{Overall Results}

Four hundred and seventy-eight people or organizations initially responded to the INL survey. For most of the data analysis, INL chose to accept only those respondents whose organizations actually owned and operated a handheld IMS, resulting in 174 responses. The other responses were used mostly to determine why the organizations did not own an IMS. The 174 responses came from 42 states. A variety of agencies owned handheld IMS units, primarily HazMat teams (20\%), fire services (14\%), local police $(12 \%)$, and sheriffs' departments $(9 \%)$. More than $80 \%$ of the respondents had more than 10 years of onthe-job experience. Respondents indicated that hazardous chemicals were the most common agents detected with the handheld IMS units, followed by explosives, illicit drugs, chemical warfare, nerve agents, and radiation.

\subsection{IMS Usage}

Of the respondents, 174 owned a handheld IMS. Figure 2 shows which handheld units they owned. The most common IMS unit reported was the Advanced Portable Detector (APD-2000), followed by ChemRae, Sabre 4000, Sabre 2000, Draeger Multi IMS, Chemical Agent Monitor-2, Chemical Agent Monitor, Vapor Tracer, and Vapor Tracer-2. Each of these units had at least six respondents who provided information for the survey. Several other IMS units had fewer than six respondents. These were grouped together in an "other" category for the graph below. Because so few responses were received about those IMS units, they were not included in further data evaluation. Other IMS units identified in the survey were Airsense, Chem Pro 100, CP100T, Environmental Vapor Monitor, Hazardous Gas and Vapor Identifier, IMS 2000E, Lightweight Chemical Detector (LCD-FR), LCD-3, M90-D1, Mobile Trace, and Sabre FR. Some agencies owned more than one handheld IMS, as shown in Figure 2.

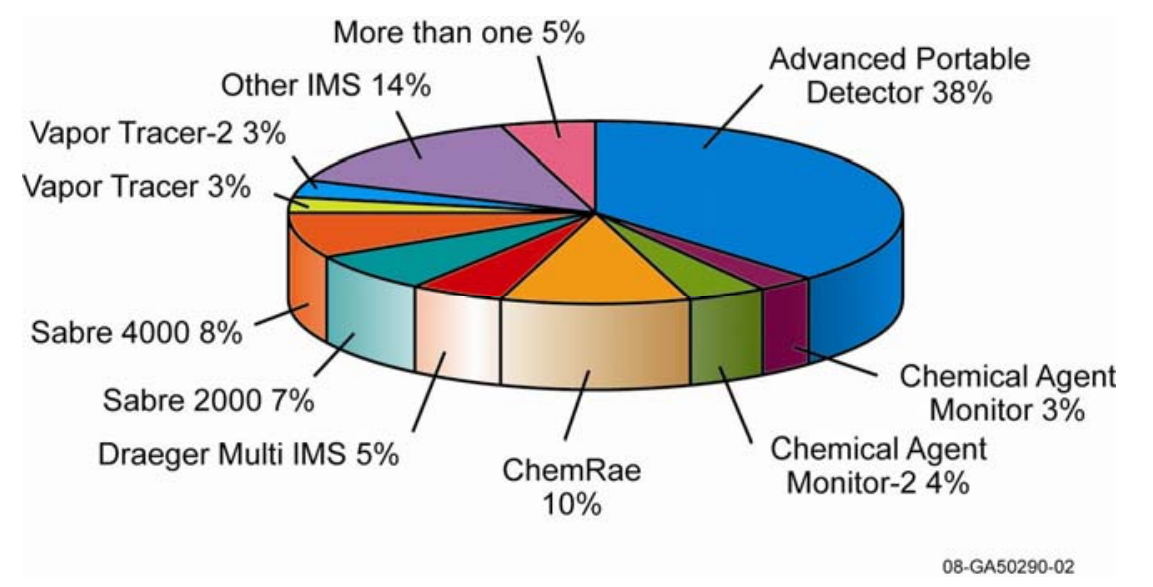

Figure 2. Total handheld IMS units owned distributed by model.

Respondents covered a range of potential users. Figure 3 shows the distribution of handheld IMS units, sorted by agency. HazMat teams (20\%), fire services (14\%), local police (12\%), and sheriff departments $(9 \%)$ were the primary owners of handheld IMS units. 


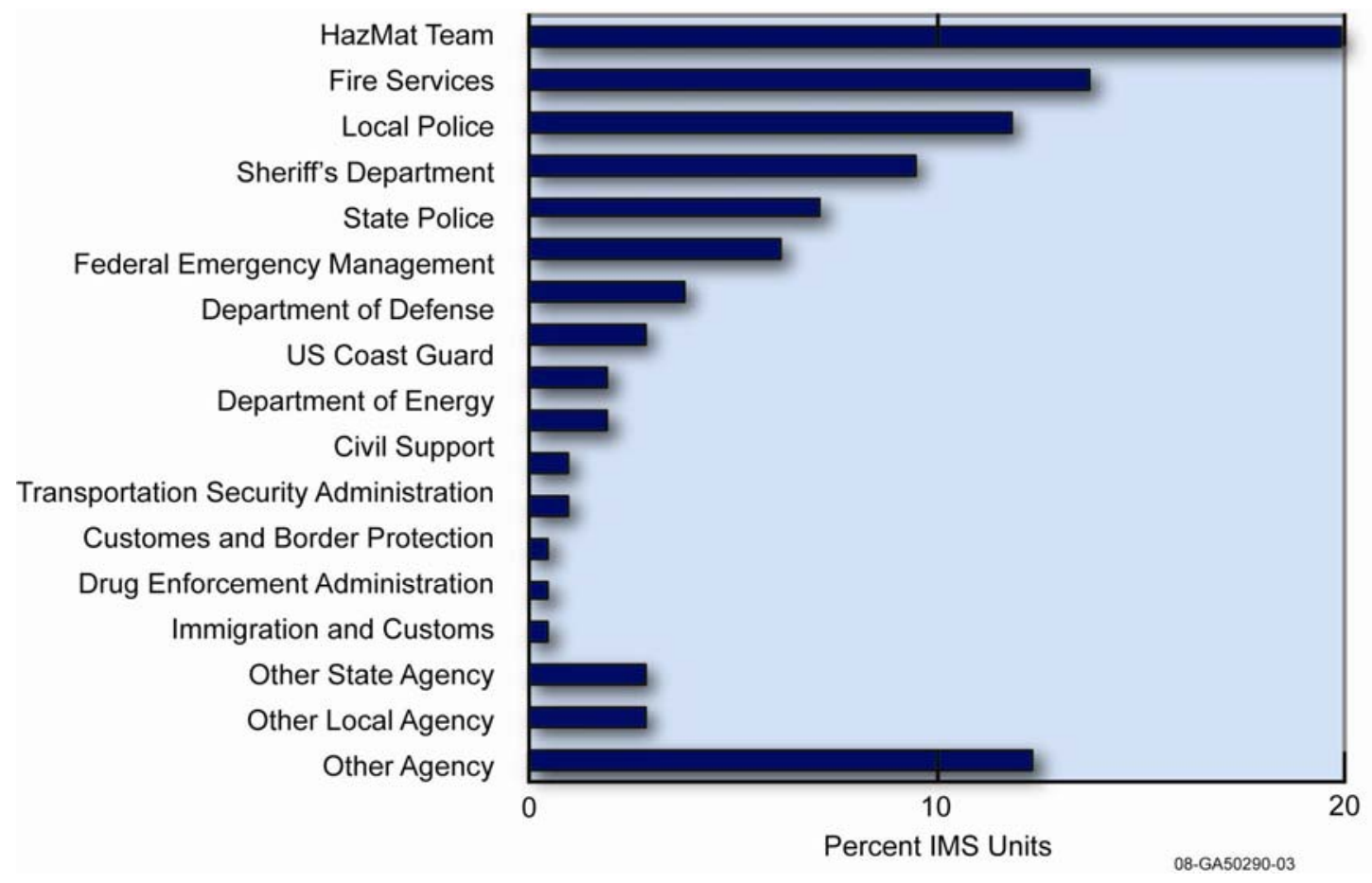

Figure 3. Distribution of handheld IMS units by agency.

\subsubsection{IMS Models Used in Regions and Cities of Varying Populations}

The survey included respondents from regions with a broad range of population density. Categories included (1) fewer than $100 \mathrm{~K}$, (2) 100-500K, (3) $501 \mathrm{k}-1 \mathrm{M}$, and (4) greater than $1 \mathrm{M}$. As shown in Figure 4, there was general use of all IMS units across regions of all population densities.

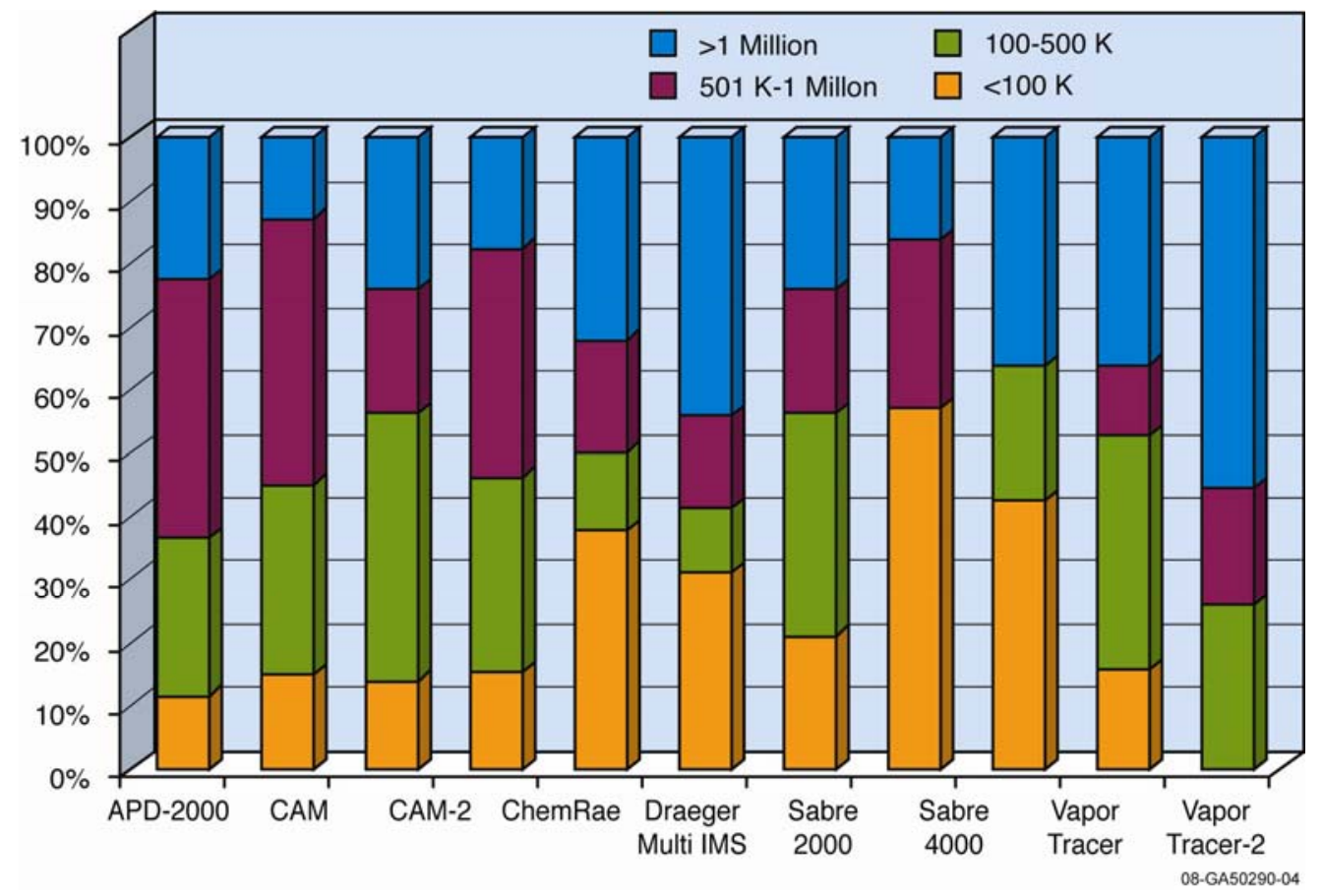

Figure 4. Distribution of models of IMS units owned based on population. 


\subsubsection{Number of Field Operations that Survey Respondents Perform Monthly}

When asked how many field operations were performed each month, nearly $60 \%$ of the owners said that they perform five or fewer operations per month. Of the remaining respondents, $20 \%$ said they perform 6-20 operations per month, 4\% perform $21-40$ operations per month, $2 \%$ perform $41-60$ operations per month, $1 \%$ perform $61-80$ operations per month, $2 \%$ perform $81-100$ operations per month, and 5\% perform greater than 100 field operations per month. During these operations, $23 \%$ of the respondents reported they use a handheld IMS unit one time per month, and $21 \%$ use the IMS unit 2-5 times per month.

\subsection{Purchasing Correlations}

Survey respondents who obtained the IMS through a direct purchase provided the following responses:

- They received more than 8 hours of training.

- Their level of satisfaction with the operation of their IMS ranged from somewhat to highly satisfied.

- They used their IMS units to detect illicit drugs or explosives rather than hazardous chemicals or chemical warfare agents.

- Fertilizer and cigarette smoke were identified as potential interferents, but not ammonia or smoke.

Respondents who obtained the IMS through a DHS grant provided the following responses:

- Their level of satisfaction with the operation of their IMS was either satisfied or mostly satisfied.

- $\quad$ They used their IMS units to detect hazardous chemicals or chemical warfare agents, but also radiation and nerve agents. They seldom detected illicit drugs or explosives.

- They usually had some training, but it was less than 8 hours.

- They lived in cities with populations ranging from $>501 \mathrm{~K}$ to $1 \mathrm{M}$.

- Ammonia was identified as an interferent, but other interferents were seldom reported.

\subsubsection{Reasons for Purchasing IMS Technology}

The major reasons given for obtaining the IMS unit were (1) to compliment or use in conjunction with other technologies and (2) to satisfy specific agency requirements, like "required as a part of a regional response team." The respondents clearly documented that they were not put in a position where they had to choose IMS technology over another technology. Some agencies were simply issued their IMS unit and did not participate in the decision making. If the agency had a choice in choosing the instrument, the agency tended to either select IMS technology for a specific feature or to upgrade from an earlier model. Additional reasons given for selecting particular IMS technologies were (1) experience with the company's products, (2) availability of the technology at the time of purchase, and (3) the particular IMS unit was listed on an authorized equipment list. Respondents also reported other reasons for purchasing a particular technology, such as the "instrument [was] on responder knowledge base," and the instrument "meets requirements for FIRESCOPE Type 1HM Company."

\subsubsection{Why Some Agencies Do Not Own IMS Technology}

Of the 478 people or organizations who initiated a response to the IMS survey, 174 owned and operated a handheld IMS. When INL asked the remaining respondents why they did not own or use a handheld IMS, $71 \%$ suggested that the main reason was cost and $12 \%$ specified that they could borrow 
the unit from another agency if needed. The remaining respondents either believed the handheld IMS unit was not needed, were in the process of purchasing a unit, or did not know why.

For populations of fewer than $100 \mathrm{~K}$, cost was the predominate reason for not owning an IMS. However, cost was not a major deterrent for populations greater than $1 \mathrm{M}$. Of the respondents serving a population of fewer than $100 \mathrm{~K}, 92 \%$ stated cost was the reason for not having an IMS, compared to $64 \%$ serving a population from $100-500 \mathrm{~K}$, and $67 \%$ serving a population from $501-1 \mathrm{M}$. Populations greater than $1 \mathrm{M}$ stated cost was a factor only $18 \%$ of the time.

\subsubsection{How the IMS Units were Obtained}

Figure 5 shows the distribution of how IMS units were purchased, and Table 1 shows the breakdown by particular instrument. Overall, DHS grants and direct purchase were the main routes for purchasing an IMS. The handheld IMS was obtained by a DHS grant $41 \%$ of the time and by direct purchase $29 \%$ of the time. Of the remaining respondents, $13 \%$ did not know how the IMS was obtained, $8 \%$ received the IMS through another agency, $6 \%$ borrowed or rented the IMS unit, and 3\% of the respondents had the unit issued to them.

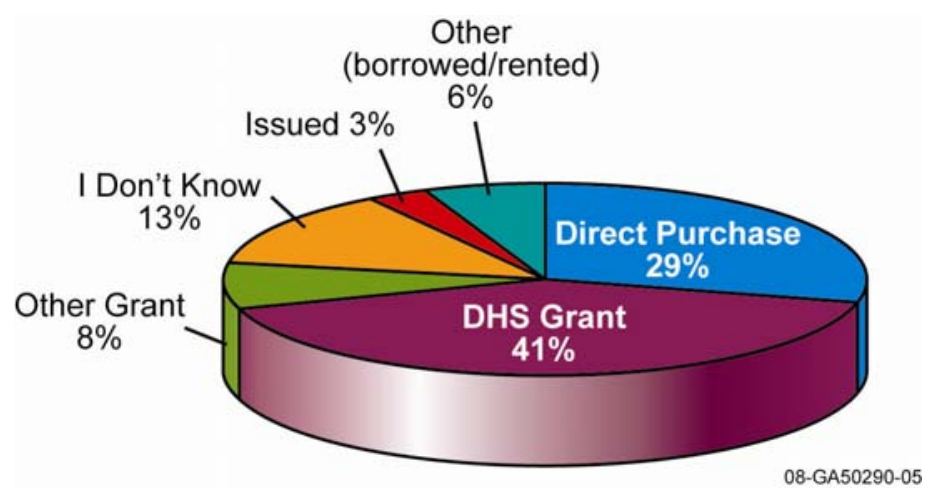

Figure 5. Distribution of how IMS units were obtained.

Table 1. Distribution of responses identifying how specific models of IMS units were obtained.

\begin{tabular}{|l|c|c|c|c|c|c|}
\hline \multirow{2}{*}{\begin{tabular}{|c|c|} 
Instrument \\
\cline { 2 - 7 }
\end{tabular}} & $\begin{array}{c}\text { Direct } \\
\text { Purchase (\%) }\end{array}$ & $\begin{array}{c}\text { DHS Grant } \\
(\%)\end{array}$ & $\begin{array}{c}\text { Other } \\
\text { Grant (\%) }\end{array}$ & $\begin{array}{c}\text { Unknown } \\
(\%)\end{array}$ & $\begin{array}{c}\text { Issued } \\
(\%)\end{array}$ & $\begin{array}{c}\text { Borrowed or } \\
\text { Rented (\%) }\end{array}$ \\
\hline APD-2000 & 25 & 56 & 6 & 5 & 5 & 3 \\
\hline CAM & 49 & 17 & 0 & 17 & 17 & 0 \\
\hline CAM 2 & 25 & 50 & 0 & 25 & 0 & 0 \\
\hline ChemRae & 12 & 35 & 12 & 24 & 11 & 6 \\
\hline Draeger Multi IMS & 22 & 45 & 22 & 11 & 0 & 0 \\
\hline Sabre 2000 & 34 & 22 & 0 & 22 & 0 & 22 \\
\hline Sabre 4000 & 40 & 40 & 20 & 0 & 0 & 0 \\
\hline Vapor Tracer & 20 & 20 & 20 & 20 & 0 & 20 \\
\hline Vapor Tracer-2 & 100 & 0 & 0 & 0 & 0 & 0 \\
\hline
\end{tabular}




\subsection{User Information}

\subsubsection{Interferents or Limitations Noted About IMS Use}

As described in Section 2, IMS is prone to masking and misidentification of analytes. To better determine the characteristics of these interferents or limitations, respondents were asked several questions about their experience. Figure 6 groups the responses across all respondents. The most frequent interferents identified were ammonia (21\%), smoke (23\%), fertilizer (17\%), and cigarette smoke (12\%). Additional interferents, categorized as "Other," account for $27 \%$ of the responses and included humidity, cleaning solvents, diesel exhaust, dust, explosives, hair spray, hand cream, nitrates, shop chemicals, and tetrahydrocannabinol (Figure 6). Figure 7 shows the IMS limitations based on the agency. HazMat teams, fire services, and the Federal Emergency Management Agency (FEMA) noted the most limitations with handheld IMS units.

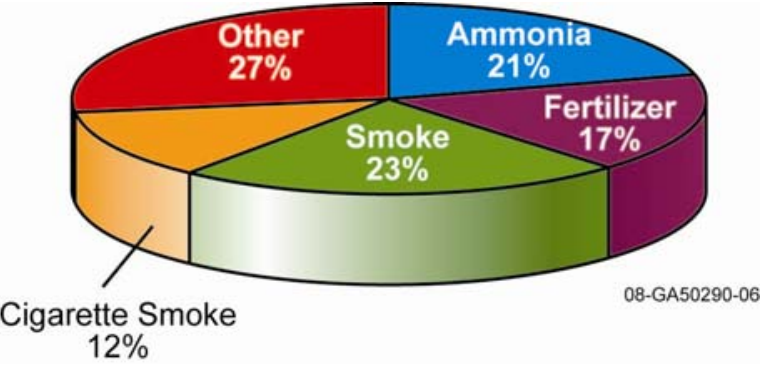

Figure 6. Distribution of types of handheld IMS limitations reported.

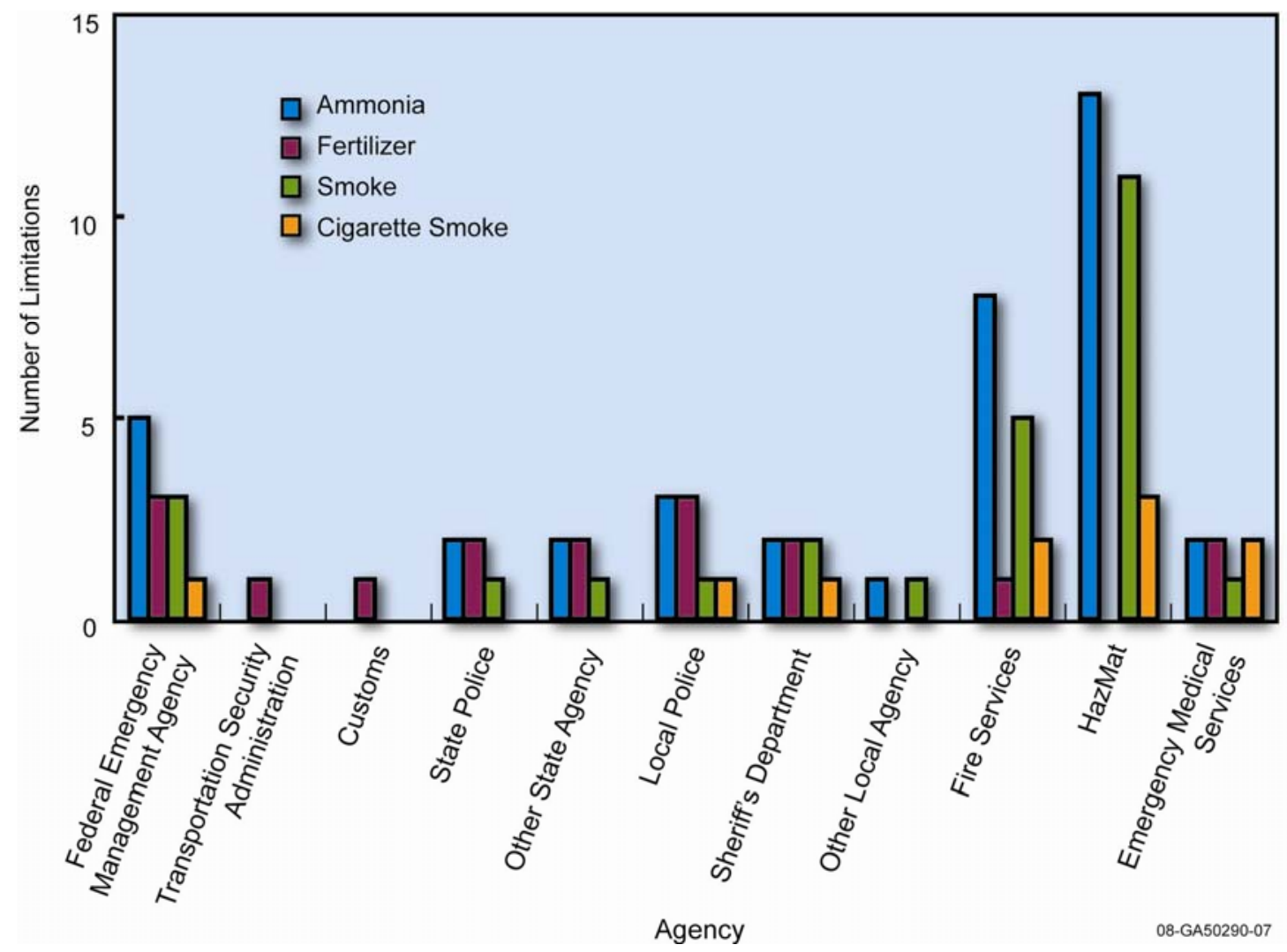

Figure 7. Distribution of types of IMS limitations reported based on responding agency. 


\subsubsection{Effectiveness and Reliability of IMS Data}

Of the respondents who owned handheld IMS units, $68 \%$ believed that IMS meets their needs. The same percentage of respondents used the IMS unit as part of a systematic approach to an incident scene investigation. Of the respondents who owned IMS units, 55\% reported that the handheld IMS unit provided the necessary data to make a decision during the incident.

Most of the respondents (55\%) require qualitative results when using the handheld IMS; however, $19 \%$ of the owners stated that they require quantitative results. The remaining respondents did not know what type of response was required when using the IMS.

Calibration standards were used by $71 \%$ of the owners to verify IMS operation, whereas $17 \%$ of the respondents do not have a calibration standard. The remaining respondents did not know if they have a calibration standard. For $94 \%$ of the owners, the predominant provider of the calibration standard was the manufacturer of the IMS unit.

\subsubsection{Analytes that are Detected}

Fifty-five percent of the respondents reported they use IMS to detect hazardous chemicals. Figure 8 shows the percentage of users who report using the IMS to detect hazardous chemicals, explosives, illicit drugs, chemical warfare, nerve agents, and radiation. One handheld IMS unit was reported to have dual capabilities as a radiation detector. Table 2 shows a breakdown of the IMS instruments by the analytes that survey respondents detect using each IMS instrument.

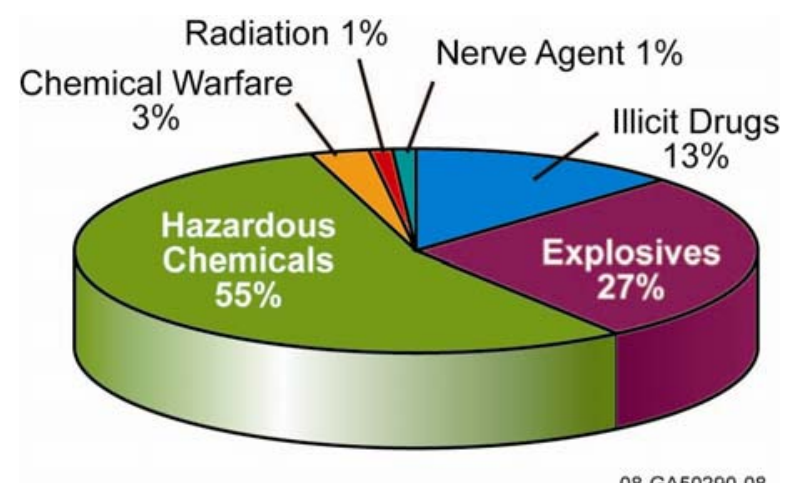

Figure 8. Distribution of agents detected using handheld IMS. 
Table 2. Distribution of responses identifying which analytes are detected based on specific IMS models.

\begin{tabular}{|l|c|c|c|c|c|c|}
\hline & \multicolumn{7}{|c|}{ Analytes Detected } \\
\cline { 2 - 7 } \multicolumn{1}{|c|}{ Instrument } & $\begin{array}{c}\text { Illicit } \\
\text { Drugs (\%) }\end{array}$ & $\begin{array}{c}\text { Explosives } \\
(\%)\end{array}$ & $\begin{array}{c}\text { Hazardous } \\
\text { Chemicals } \\
(\%)\end{array}$ & $\begin{array}{c}\text { Chemical } \\
\text { Warfare } \\
(\%)\end{array}$ & $\begin{array}{c}\text { Radiation } \\
(\%)\end{array}$ & $\begin{array}{c}\text { Nerve } \\
\text { Agents } \\
(\%)\end{array}$ \\
\hline APD-2000 & 3 & 14 & 70 & 7 & 3 & 3 \\
\hline CAM & 11 & 22 & 67 & 0 & 0 & 0 \\
\hline CAM 2 & 0 & 29 & 71 & 0 & 0 & 0 \\
\hline ChemRae & 5 & 38 & 57 & 0 & 0 & 0 \\
\hline Draeger Multi IMS & 0 & 9 & 82 & 9 & 0 & 0 \\
\hline Sabre 2000 & 20 & 40 & 40 & 0 & 0 & 0 \\
\hline Sabre 4000 & 30 & 36 & 33 & 0 & 0 & 0 \\
\hline Vapor Tracer & 33 & 67 & 0 & 0 & 0 & 0 \\
\hline Vapor Tracer-2 & 33 & 67 & 0 & 0 & 0 & 0 \\
\hline
\end{tabular}

\subsection{Training and Overall Satisfaction}

Questions on the survey asked respondents to rate their overall satisfaction with their handheld IMS. Listed categories were as follows: (1) not satisfied, (2) somewhat satisfied, (3) satisfied, (4) mostly satisfied, and (5) highly satisfied. Table 3 displays the percent responses in each category for each of the IMS units identified. In addition, a weighted average was calculated for each instrument. The majority of handheld IMS users were either somewhat satisfied or satisfied with the instrument.

Table 3. Distribution of survey respondents and satisfaction with their handheld IMS units.

\begin{tabular}{|l|c|c|c|c|c|}
\hline \multirow{2}{*}{\multicolumn{1}{|c|}{ Instrument }} & \multicolumn{5}{|c|}{ Satisfaction Category } \\
\cline { 2 - 6 } & $\begin{array}{c}\text { Sot } \\
(\%)\end{array}$ & $\begin{array}{c}\text { Somewhat } \\
\text { Satisfied } \\
(\%)\end{array}$ & $\begin{array}{c}\text { Satisfied } \\
(\%)\end{array}$ & $\begin{array}{c}\text { Mostly } \\
\text { Satisfied } \\
(\%)\end{array}$ & $\begin{array}{c}\text { Highly } \\
\text { Satisfied } \\
(\%)\end{array}$ \\
\hline APD-2000 & 19 & 39 & 23 & 14 & 5 \\
\hline CAM & 0 & 50 & 33 & 17 & 0 \\
\hline CAM 2 & 0 & 20 & 80 & 0 & 0 \\
\hline ChemRae & 27 & 20 & 27 & 27 & 0 \\
\hline Draeger Multi IMS & 34 & 11 & 33 & 11 & 11 \\
\hline Sabre 2000 & 18 & 9 & 46 & 18 & 9 \\
\hline Sabre 4000 & 0 & 21 & 29 & 43 & 7 \\
\hline Vapor Tracer & 75 & 25 & 0 & 0 & 0 \\
\hline Vapor Tracer-2 & 0 & 75 & 0 & 0 & 25 \\
\hline
\end{tabular}

Table 4 shows the amount of training users reported receiving for the respective handheld IMS instruments. As the data in the table show, many respondents had fewer than 8 hours of training, some had 1-3 days of training, and a smaller number had more extensive training. 
Table 4. Distribution of reported amount of training received based on individual IMS unit.

\begin{tabular}{|l|c|c|c|c|c|c|}
\hline \multirow{2}{*}{\begin{tabular}{|c|} 
Instrument \\
\cline { 2 - 7 }
\end{tabular}} & $\begin{array}{c}\text { No Training } \\
(\%)\end{array}$ & $\begin{array}{c}\text { Fewer than } 8 \\
\text { Hrs (\%) }\end{array}$ & $\begin{array}{c}1-3 \text { Days } \\
(\%)\end{array}$ & $\begin{array}{c}4-6 \text { Days } \\
(\%)\end{array}$ & $\begin{array}{c}1 \text { Wk } \\
(\%)\end{array}$ & $\begin{array}{c}>1 \text { Wk } \\
(\%)\end{array}$ \\
\hline APD-2000 & 7 & 69 & 13 & 5 & 2 & 4 \\
\hline CAM & 0 & 25 & 25 & 0 & 25 & 25 \\
\hline CAM 2 & 0 & 100 & 0 & 0 & 0 & 0 \\
\hline ChemRae & 26 & 53 & 0 & 7 & 7 & 7 \\
\hline Draeger Multi IMS & 11 & 78 & 11 & 0 & 0 & 0 \\
\hline Sabre 2000 & 11 & 45 & 33 & 0 & 11 & 0 \\
\hline Sabre 4000 & 0 & 23 & 69 & 0 & 0 & 8 \\
\hline Vapor Tracer & 40 & 20 & 20 & 0 & 20 & 0 \\
\hline Vapor Tracer-2 & 20 & 20 & 20 & 20 & 0 & 20 \\
\hline
\end{tabular}

Using the Pearson $r$ correlation described earlier, the following correlations were established between satisfaction, training, and some other factors:

- Respondents who had no training or fewer than 8 hours of training were not satisfied with their IMS.

- Respondents with fewer than 8 hours of training obtained their IMS through a DHS grant.

- Respondents who were not satisfied with their IMS also:

- Had no training or less than 8 hours of training.

- Were unable to identify any specific interferents.

- Were usually from cities of fewer than $100 \mathrm{~K}$.

- Detected illicit drugs and explosives.

- Respondents who were highly satisfied also reported that they:

- Obtained the IMS unit through a direct purchase.

- Were from cities greater than $1 \mathrm{M}$.

- Observed fertilizer and cigarette smoke as interferents.

\subsection{IMS Units' Effectiveness in Providing Needed Data}

Handheld IMS owners provided the following comments when answering if the unit provides the necessary data:

- "Sometimes. Usually it just verifies what is not there."

- "Depends on the incident."

- "Parts of data, not all."

- "A small part of the information required."

- "Somewhat, as long as it is paired with another technology."

- "Not by itself, must be backed up." 
- "It is part of the overall evaluation process."

- "Provides data according to one technology."

Specific user experience for ion mobility spectrometers follow. Of the departments that owned handheld IMS units, respondents representing populations of fewer than $100 \mathrm{~K}$ gave the following comments about IMS units:

- "Used as a piece of detection equipment and nothing more."

- "Very minimal use, very little training."

- "Not practical to use in the field operations. Recommend purchasing K-9's."

- "Good screening instrument to look for target analytes of interest."

- "Use on suspect packages."

- "Use to 'rule out' initial unknowns."

Respondents representing populations of $100 \mathrm{~K}-500 \mathrm{~K}$ indicated the following about their experience with handheld IMS units:

- "Used in training only."

- "The technology is capable of a much wider application than it is used for."

- Used as "another tool to narrow down the field."

- "Lots of false positives."

- "Used on every call out."

- "Maintenance intensive and unreliable."

- "Not satisfied with present technology."

- "Use for unidentified chemicals."

Respondents representing populations of $501 \mathrm{~K}-1 \mathrm{M}$ detailed the following about their experience with handheld IMS units:

- "It's one tool in the toolbox."

- "Serves as a tool to determine level of personal protective equipment."

- "Don't use because of the constant calibrations needed."

- "Too hard to calibrate false positives."

- "Use to identify nerve agents."

- Use to "prescreen patients for emergency room."

Respondents representing populations greater than $1 \mathrm{M}$ gave the following comments about their experience with handheld IMS units:

- "Don't care for IMS technology with Gas Chromatography/Mass Spectrometry and Fourier transform infrared readily available."

- "Don't totally understand the use and limitations of the device."

- "Many other detectors are required to make decisions." 
- "Should be paired with other technologies to ensure no gaps."

- "Very user friendly."

- "Used on all white powder alarms."

- "IMS is great technology for detection when used in the proper setting."

- "When canines are not present, then the handheld detectors are utilized."

- "Prone to false alarms."

- Used "during boarding searches of suspected narcotic smugglers." 


\section{CONCLUSIONS}

When responding to an incident, first responders need accurate information to assess hazards, evaluate the level of risk, and make critical decisions. Handheld IMS units are used by these responders to help determine the nature and magnitude of the chemical threat to the responders, the public, and the environment. This report gathered information about handheld IMS units and collected user information

through an Internet survey. In general, as identified in previous work at INL, survey respondents indicate that manufacturers make some claims for instruments that cannot be supported in field applications, and sometimes instruments did not meet actual needs.

The following findings were identified:

1. IMS units are seldom used as part of an integrated system for detecting and identifying chemicals, but instead, are often used independently.

2. Most survey respondents used IMS for qualitative analysis, not for quantification.

3. Respondents are generally confused about the capabilities of their IMS unit. This is probably because of a lack of training.

4. The most common IMS unit used by survey respondents was the Advanced Portable Detector (APD2000), followed in order by ChemRae, Sabre 4000, Sabre 2000, Draeger Multi IMS, Chemical Agent Monitor-2, Chemical Agent Monitor, Vapor Tracer and Vapor Tracer-2.

5. HazMat teams (20\%), fire services (14\%), local police (12\%), and sheriffs' departments (9\%) were the primary owners of handheld IMS units.

6. IMS units were used for detecting a range of analytes. The most common use was for hazardous chemicals, followed by explosives, illicit drugs, chemical warfare, nerve agents and radiation. One IMS unit has dual capability as a radiation detector.

7. Those respondents who did not own an IMS listed cost as the main factor.

8. Respondents who had no training or fewer than 8 hours of training were not satisfied with the overall operation of the handheld IMS unit. 


\section{RECOMMENDATIONS}

1. IMS instruments are susceptible to interferents and other factors that warrant a well-informed user in some situations. Therefore, in order to improve accuracy and effectiveness of IMS measurements and to improve overall satisfaction with instrument performance, we recommend that all IMS users receive at least 8 hours of training and preferably 24 hours or more of training.

2. Most IMS users do not have an independent check on the reliability of their measurements. Therefore, we suggest that there be an independent performance evaluation of the field use of different types of handheld IMS units to determine their ability to provide decision quality data. 


\section{REFERENCES}

1. Daum, K.A., M.G. Watrous, M.D. Neptune, D.I. Michael, K.J. Hull, J.D. Evans, "Data for First Responder Use of Photoionization Detectors for Vapor Chemical Constituents," May 2005, INL/EXT 05-00165.

2. Fox, S.L., K. A. Daum, C. J. Miller, M. M Cortez, "Emergency First Responders' Experience with Colorimetric Detection Methods," October 2007, INL/EXT 07-12644.

3. Hill Jr., H.H., W.F. Siems, R.H. StLouis, and D.G. McMinn, "Ion Mobility Spectrometry," Analytical Chemistry, Vol. 62, No. 23, 1990, pp. 1201A-1209A.

4. Eiceman, G.A., and Z. Karpas, Ion Mobility Spectrometry, 1st ed., CRC Press, 1994, pg. 21.

5. Lopez-Avila, V., and H.H. Hill Jr., "Field Analytical Chemistry," Analytical Chemistry, Vol. 69, No. 12 pp. 289R-305R.

6. Brittain, A.H., and J.L. Brokenshire, "Quantitative Investigation of the Ion Mobility (IMS) Detection of Nitro-Compounds over a Wide Temperature Range, and the Effects of Dopants," Jackson, Wyoming, Fifth International Workshop on Ion Mobility Spectrometry, 1996.

7. Proctor, C.J., and J.F.J. Todd, “Alternative Reagent Ions for Plasma Chromatography," Analytical Chemistry, Vol. 56, No. 11, 1984, pp. 1794-1797.

8. Lawrence, A.H., and P. Neudorfl, "Detection of Ethylene Glycol Dinitrate Vapors by Ion Mobility Spectrometry Using Chloride Reagent Ions," Analytical Chemistry, Vol. 60, 1988, pp. 104-109.

9. Daum, K.A., D.A. Adkinson, R.G. Ewing, W.B. Knighton, and E.P. Grimsrud, "Resolving Interferences in Negative Mode Ion Mobility Spectrometry Using Selective Reactant Ion Chemistry," Talanta, Vol. 54, No. 2, 2001, pp. 299-309.

10. Karasek, F.W., and O.S. Tatone, "Plasma Chromatography of the Mono-Halogenated Benzenes," Analytical Chemistry, Vol. 44, No. 11, pp. 1758-1763.

11. Cohen, M.J., "Time of Flight Ion Analysis with a Pulsed Ion Source Employing Ion-Molecule Reactions," 1971: U.S. Patent \#3593018.

12. Carroll, D.I., M.J. Cohen, and R.E. Wernlund, "Enhanced Resolution of Measurements of Trace Gases Which Undergo Ion-Molecule Reactions,” 1971: U.S. Patent \#3626180.

13. Carroll, D.I., “Apparatus and Methods for Separating, Detecting, and Measuring Trace Gases,” 1972: U.S. Patent \#3668383.

14. Cohen, M.J., D.I. Carroll, R.E. Wernlund, and W.D. Kilpatrick, “Apparatus and Methods for Separating, Concentrating, Accelerating, and Measuring Trace Gases,” 1972: U.S. Patent \#3699333.

15. Cohen, M.J., and K. Crowe, "Apparatus and Methods for Detecting, Separating, Concentrating, and Measuring Electronegative Trace Vapors.” 1973: U.S. Patent \#3742213.

16. Karasek, F.W., "Plasma Chromatography,” Analytical Chemistry, Vol. 46, 1974, pp. 710A-717A.

17. Karasek, F.W., and D.W. Denney, "Detection of 2,4,6-Trinitrotoluene Vapours in Air by Plasma Chromatography," Journal of Chromatography, Vol. 93, 1974, pp. 141-147.

18. Karasek, F.W., H.H. Hill, S.H. Kim, and S. Rokushika, "Gas-Chromatographic Detection Modes for Plasma Chromatograph,” Journal of Chromatography, Vol. 135, 1977, pp. 329-339.

19. Karasek, F.W., and D.M. Kane, "Plasma Chromatography of N Alkyl Alcohols," Journal of Chromatographic Science, Vol. 10, 1972, pp. 673-677. 
20. Karasek, F.W., and D.M. Kane, "Effect of Oxygen on Response of the Electron-Capture Detector," Analytical Chemistry, Vol. 45, No. 3, 1973, pp. 576-580.

21. Karasek, F.W., O.S. Tatone, and D.M. Kane, "Study of Electron Capture Behavior of Substituted Aromatics by Plasma Chromatography," Analytical Chemistry, Vol. 45, No. 7, 1973, pp. 1210-1214.

22. Spangler, G.E., J.P. Carrico, and D.N. Campbell, "Recent Advances in Ion Mobility Spectrometry for Explosives Vapor Detection," Journal of Testing and Evaluation, Vol. 13, No. 3, 1985, pp. 234-240.

23. Baim, M.A. and H.H. Hill Jr., "Tunable Selective Detection for Capillary Gas-Chromatography," Analytical Chemistry, Vol. 54, 1982, pp. 38-43.

24. Wu, C., et al, "Surface Ionization Ion Mobility Spectrometry," Analytical Chemistry, Vol. 71, No. 1, pp. 273-278.

25. Kolaitis, L., and D.M. Lubman, “Atmospheric-Pressure Ionization Mass-Spectrometry with LaserProduced Ions”, Analytical Chemistry, Vol. 58, pp. 1993-2001.

26. Asbury, G.R., J. Klasmeir, and H.H. Hill Jr., "Analysis of Explosives Using Electrospray Ionization/Ion Mobility Spectrometry (ESI/IMS),” Talanta, Vol. 50, 2000, pp. 1291-1298.

27. Begley, P., R. Corbin, B.E. Foulger, and P.G. Simmonds, "Photoemissive Ionization Source for Ion Mobility," Journal of Chromatography, Vol. 588, 1991, pp. 239-245.

28. Knighton, W.B., J.A. Bognar, P.M. O’Connor, and E.P. Grimsrud, "Gas-Phase SN2 Reactions of Chloride Ion with Alkyl Bromides at Atmospheric Pressure. Temperature Dependence of the Rate Constants and Energies of the Transition States," Journal of the American Chemical Society, Vol 115, No. 25, 1993, pp. 12079-12084.

29. Daum, K.A., D.A. Atkinson, and R.G. Ewing, "The Role of Oxygen in the Formation of TNT Product Ions in Ion Mobility Spectrometry," International Journal of Mass Spectrometry, Vol. 214, 2002, pp. 257-267.

30. Eiceman, G.A., and J.E. Parmeter, "Evaluation of a Test Protocol for Explosives Trace Detectors Using a Representative Commerical Analyzer," National Institute of Justice, 1999, p. 28.

31. Daum, K.A., D.A. Atkinson, and R.G. Ewing, "Formation of Halide Reactant Ions and Effects of Excess Reagent Chemical on the Ionization of TNT in Ion Mobility Spectrometry," Talanta, Vol. 55, No. 4, pp. 491-500. 